\title{
Functionalized Poplar Powder as a Support Material for Immobilization of Enoate Reductase and a Cofactor Regeneration System ${ }^{\mathrm{S}}$
}

\author{
Han Li, Xiumei Cui, and Liangyu Zheng* \\ Key Laboratory for Molecular Enzymology and Engineering of the Ministry of Education, College of Life Sciences, Jilin University, \\ Changchun 130012, P. R. China
}

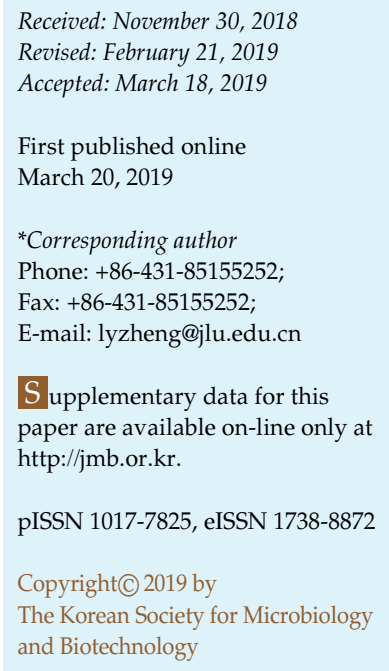

In this study, functionalized poplar powder (FPP) was used as a support material for the immobilization of enoate reductase (ER) and glucose-6-phosphate dehydrogenase (GDH) by covalent binding. Under optimal conditions, the immobilization efficiency of ER-FPP and GDH-FPP was $95.1 \%$ and $84.7 \%$, and the activity recovery of ER and GDH was $47.5 \%$ and $37.8 \%$, respectively. Scanning electron microscopy (SEM) and energy dispersive spectroscopy (EDS) analysis indicated that FPP was a suitable carrier for enzyme immobilization. ER-FPP and GDH-FPP exhibit excellent thermal stabilities and superior reusability. Especially, ER-FPP and GDH-FPP enable the continuous conversion of 4-(4-Methoxyphenyl)-3-buten-2-one with $\mathrm{NAD}^{+}$recycling. While the immobilization strategies established here were simple and inexpensive, they exploited a new method for the immobilization and application of ER and its cofactor recycling system.

Keywords: Enoate reductase, functionalized poplar powder, covalent immobilization, cofactor regeneration system

\section{Introduction}

Enoate reductases (ERs), from the 'Old Yellow Enzyme' family of flavor proteins, are widely distributed in microorganisms-particularly in bacteria and lower fungiand in plants $[1,2]$. They are able to reduce a wide range of activated alkenes, such as $\alpha, \beta$-unsaturated aldehydes, ketones, carboxylic acids and derivatives (esters, lactones, cyclic imides, and cyclic acid anhydrides), and $\alpha, \beta$ unsaturated nitroalkene, employing nicotinamide $[\mathrm{NAD}(\mathrm{P}) \mathrm{H}]$ as a cofactor, and providing products with a variety of biotechnological and pharmaceutical applications [3-6]. Despite the remarkable synthetic potential of ERs, the wide spread use of purified ERs in bio-catalysis is limited due to the high cost of the cofactors [7]. So, it is necessary to establish cofactor regeneration system for preparative applications of ER.

Natural or engineered whole-cell systems can allow in situ cofactor recycling, and provide a natural environment for enzyme [8]. However, bioconversions using whole cells have some drawbacks such as substrate or product toxicity to the cells, poor permeability of substrate or product, formation of by-product, and difficult isolation of products following catalysis [9]. The immobilization of a catalytic enzyme and a cofactor-regenerating enzyme can provide an enhanced stability of the enzymes, simplify product isolation, and reduce the protein contamination from substrate or product $[10,11]$. The improved enzyme performance can also result in lower enzyme costs and increase their potential for use as industrial catalysts [12]. Herein, covalent binding is employed for the immobilization of ER and its cofactor-recycling partner enzyme GDH, where the enzymes can remain stable while bound on carriers due to a strong binding force between them [13].

Nowadays, an array of available materials such as agarose [14, 15], chitosan [16, 17], copolymer carriers [18, 19], glass beads [20], magnetic poly (ionic liquids) [21], and acrylic and styrenic resins [22, 23] are being used as insoluble carriers to provide the most straightforward route for covalent immobilization of enzymes. Nevertheless, from an industrial perspective, the cost of preparing immobilized enzymes needs to be considered even if we can establish an 
efficient immobilization strategy to obtain immobilized enzymes with excellent stabilities and reusability [10, 12]. Commodity chemical materials generally have very low added value, leaving very little space for the costs of immobilized enzymes [13]. Therefore, cheap immobilization carriers and protocols together with high reusability are the key factors that will determine whether the preparation of immobilized enzyme is successful, or whether it can be effectively used in industrial fields. On a global scale, lignocellulose is one of the most abundant substances in nature [24]. Agricultural residues such as cornstalk, pasture, wheat straw, rice husk, and poplar powder (PP) are common renewable lignocellulose resources and their low cost [25] makes them highly suitable as enzyme immobilization materials when compared with the commodity carriers.

In the present study, we explore the potential of PP as a carrier for the covalent immobilization of ER and GDH. We pretreated PP to expose the cellulose, and then the cellulose components were functionalized for covalent anchoring of the enzymes. Characterization of untreated PP, functionalized PP (FPP), and immobilized ER-FPP were done by SEM and EDS. Furthermore, the thermal stabilities of ER-FPP and GDH-FPP, the continuous catalytic reduction of 4-(4Methoxyphenyl)-3-buten-2-one, and the reusability of ERFPP and GDH-FPP were investigated. The aim of this study is to construct simple and cost-effective immobilization systems for ER and GDH.

\section{Materials and Methods}

\section{Materials}

Bovine serum albumin (BSA), NADH, and $\mathrm{NAD}^{+}$were purchased from Roche (China). Glucose, ammonium sulfate, lactic acid, formic acid, acetic acid, choline chloride, sodium hydroxide, dimethyl sulfoxide, epichlorohydrin, sodium thiosulfate, ethanediamine, glutaraldehyde, and sodium metaperiodate were purchased from Sinopharm Chemical Reagent Co., Ltd (China). Dextran (MW $70,000)$ was purchased from Energy Chemical (Shanghai, China). Polyethyleneimine solution (PEI, MW 1,300) was purchased from Shanghai Aladdin Bio-Chem Technology Co., Ltd (China). One hundred meshes of cornstalk, pasture, wheat straw, rice husk, and poplar powder were purchased from XingYi Deep Processing Factory (China). 2-Cyclohexen-1-one was purchased from Chengdu Best Chemical Reagent Co., Ltd (China). The substrate 4-(4Methoxyphenyl)-3-buten-2-one and the product 4-(4-Methoxyphenyl)butan-2-one were synthesized and purified in our laboratory [26]. ER and GDH were constructed and expressed in our laboratory [26]. The deep eutectic solvents (DESs) were prepared in our laboratory [27]. The other chemicals used in this study were of analytical grade.

\section{Pretreatment of Lignocellulosic Biomass}

In this study, lignocellulosic biomass consisting of cornstalk, pasture, wheat straw, rice husk, and poplar powder (PP) was selected for use as support materials for enzyme immobilization. The biomass $(1.0 \mathrm{~g})$ was added in a vial with DES (10.0 g). The DESs were utilized in 1:1 mole ratios of choline chloride: lactic acid ( $\mathrm{ChCl}$ : LA), choline chloride: formic acid ( $\mathrm{ChCl}$ : $\mathrm{FA})$, and choline chloride: acetic acid $(\mathrm{ChCl}$ : $\mathrm{AA})$, respectively. The vials were placed into a water bath set at $80^{\circ} \mathrm{C}$ for $2 \mathrm{~h}$. After that, the samples were filtered to separate the pre-treated biomass from the DES. The isolated biomass was then put into another vial with $15 \mathrm{ml}$ of deionized water, and shaken at $50^{\circ} \mathrm{C}$ for $20 \mathrm{~min}$, to remove the residual DES. The water-washing process was repeated 3 times. The pretreated biomass was next placed in a drying oven set at $85^{\circ} \mathrm{C}$ for $24 \mathrm{~h}$ prior to weighing, and was later evaluated by measuring the activation degree.

\section{Activation Degree Assay for Pretreated Biomass}

The pretreated biomass $(100 \mathrm{mg})$ was mixed with sodium hydroxide solution $(0.4 \mathrm{M}, 2.0 \mathrm{ml})$, dimethyl sulfoxide $(2.0 \mathrm{ml})$ and epoxy chloropropane $(2.0 \mathrm{ml})$. After the mixture was stirred for $6 \mathrm{~h}$ at room temperature, the biomass was washed with acetone and dried. Next, the biomass (50 mg of dry weight) was mixed in sodium thiosulfate solution $(1.4 \mathrm{M}, 6.0 \mathrm{ml})$ with phenolphthalein indicator $(5.0 \mathrm{~g} / \mathrm{l}, 30 \mu \mathrm{l})$. After $2 \mathrm{~h}$, dilute hydrochloric acid was used to titrate the reaction solution. The activation degree (A) of the pretreated biomass was calculated with the following equations:

$$
\mathrm{A}=\frac{c v}{m}
$$

$m$ : pre-treated biomass amount $(\mathrm{mg}) ; c$ : molar concentration of hydrochloric acid $(\mu \mathrm{M})$; $v$ : volume of hydrochloric acid consumed in titration $(\mu \mathrm{l})$.

\section{Functionalization of Pretreated PP}

The pretreated PP (1.0 g of dry weight) and sodium periodate $\left(\mathrm{NaIO}_{4}, 2.0 \mathrm{~g}\right)$ were mixed in deionized water $(50 \mathrm{ml})$, and the oxidation was carried out in darkness at $25^{\circ} \mathrm{C}$ for $22 \mathrm{~h}$. The oxidized PP (OPP) was washed 3 times with alcohol to remove the unreacted $\mathrm{NaIO}_{4}$. Then OPP was added in aqueous solution of PEI $(8 \mathrm{mM}, 50 \mathrm{ml})$ or ethanediamine $(150 \mathrm{mM}, 50 \mathrm{ml})$ to perform the amination reaction at $25^{\circ} \mathrm{C}$ for $3 \mathrm{~h}$. After the aminated OPP was washed 2 times with $50 \mathrm{ml}$ of deionized water, it was further added in deionized water containing glutaraldehyde $(50 \mathrm{mM}$, $50 \mathrm{ml})$ or oxidized dextran $(40 \mu \mathrm{M}, 50 \mathrm{ml})$, and the reactions took place at $25^{\circ} \mathrm{C}$ for $1 \mathrm{~h}$. The functionalized PP (FPP) was washed 2

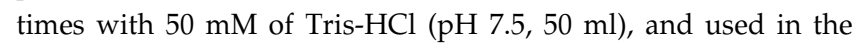
subsequent experiments.

\section{Immobilization of ER and GDH with FPP as a Support Material}

ER (10 U) or GDH (20 U) was mixed with FPP (1.0 g) in Tris$\mathrm{HCl}$ buffer (50 mM, pH 7.5, $6.0 \mathrm{ml})$. The mixtures were kept at $4{ }^{\circ} \mathrm{C}$ for $3 \mathrm{~h}$ with shaking. Then the immobilized ER and GDH were collected by centrifugation $\left(10,614 \times g, 5 \mathrm{~min}, 4^{\circ} \mathrm{C}\right)$, and washed 3 
times with Tris- $\mathrm{HCl}$ buffer ( $50 \mathrm{mM}, \mathrm{pH} 7.5)$. Parameters such as enzyme additive amount (10-60 mg), $\mathrm{pH}$ of Tris- $\mathrm{HCl}$ buffer (5.59.5), and immobilization time (1-4 h), were optimized during the immobilization process. The assay and calculation of protein amounts and enzymatic activities of ER and GDH immobilized on the functionalized biomass, and the immobilization efficiency (\%) and activity recovery (\%) of ER-FPP and GDH-FPP, were based on our previous paper [26].

\section{Morphological Characterization of Untreated PP, FPP and ER-FPP}

The morphology of untreated PP, FPP and ER-FPP was characterized with a scanning electron microscope (JEOL JSM6700F, Japan) in a field-emission FEI Inspect F operated at $3 \mathrm{kV}$. Samples were suspended in ethanol for ultrasonic dispersion, dried, and fixed onto silicon wafers. The samples were then immediately sputter-coated with platinum before observation.

The changes of elemental components on the surface of FPP and FPP-ER were analyzed by peripheral energy dispersive spectroscopy (EDS, JEOL JSM-7800F/ Oxford X-Max 80 SDD Detector).

\section{Thermal Stabilities of ER-FPP and GDH-FPP}

To study the thermal stabilities of free and immobilized ER and $\mathrm{GDH}$, their residual enzymatic activities were measured after incubation in a Tris- $\mathrm{HCl}$ buffer $(50 \mathrm{mM}, \mathrm{pH} 7.5)$ at $30^{\circ} \mathrm{C}$ and $50^{\circ} \mathrm{C}$ for a certain period of time. The maximum specific activity values of free and immobilized enzyme under initial conditions were regarded as $100 \%$, and the ratio of the specific activity obtained under other conditions to the maximum specific activity is referred to as the relative activity.

\section{Continuous Reduction of 4-(4-Methoxyphenyl)-3-Buten-2-One by ER-FPP and GDH-FPP}

The substrate 4-(4-Methoxyphenyl)-3-buten-2-one $(50 \mu \mathrm{M})$, glucose $(2.0 \mathrm{mM})$ and $\mathrm{NAD}^{+}(100 \mu \mathrm{M})$ were added in Tris- $\mathrm{HCl}$ buffer $(50 \mathrm{mM}, \mathrm{pH} 7.5,2.0 \mathrm{ml})$ with ER-FPP (3.5 U) and GDH-FPP $(7.0 \mathrm{U})$, and the resulting mixture was stirred at $30^{\circ} \mathrm{C}$. After every $8 \mathrm{~h}$, new substrate $(50 \mu \mathrm{M})$ and glucose $(2.0 \mathrm{mM})$ were added in the reaction system, and this step was repeated six times. The reaction samples of each round were removed and injected into the high-performance liquid chromatography (HPLC) system for analysis. The reduction of 4-(4-Methoxyphenyl)-3-buten-2-one was monitored through HPLC (P230p, Dalian Elite Analytical Instruments Co., Ltd) using an Elite C18 column. The mobile phase was a mixture of methanol/deionized water $(60 / 40, \mathrm{v} / \mathrm{v})$ at a flow rate of $0.8 \mathrm{ml} / \mathrm{min}$. UV detection at $215 \mathrm{~nm}$ was employed for quantification. The retention time of the product 4-(4-Methoxyphenyl)butan-2-one was $10.2 \mathrm{~min}$, which was confirmed based on its standard (purity $>99.5 \%$ ), and the conversions were confirmed by external standard method.

\section{Reusability of the Mixture of ER-FPP and GDH-FPP}

The reaction system $(2.0 \mathrm{ml})$ consisted of ER-FPP (3.5 U), GDHFPP (7.0 U), 4-(4-Methoxyphenyl)-3-buten-2-one (0.5 mM), glucose
(50 $\mathrm{mM})$, and $\mathrm{NAD}^{+}(1.0 \mathrm{mM})$ in Tris- $\mathrm{HCl}$ buffer (50 mM, pH 7.5). Each cycle lasted for $3 \mathrm{~h}$ at $30^{\circ} \mathrm{C}$, followed by separation of ERFPP and GDH-FPP from the reaction system by centrifugation. After thorough washing with Tris- $\mathrm{HCl}$ buffer $(50 \mathrm{mM}, \mathrm{pH} 7.5)$, the mixture of ER-FPP and GDH-FPP was re-suspended in a fresh reaction system, and repeatedly used for the next reaction cycle under the same reaction conditions. The relative ER activities of the ER-FPP and GDH-FPP mixture were calculated by regarding the enzyme activity of ER in the first cycle as $100 \%$.

\section{Results and Discussion}

\section{Pretreatment of Lignocellulosic Biomass}

Herein, five lignocellulosic biomasses including cornstalk, pasture, wheat straw, rice husk and poplar powder, were selected as support materials for the immobilization of ER and GDH by covalent binding. The immobilization is mainly based on the exposed hydroxyl groups of cellulose on biomass. However, lignocellulosic biomass is mainly composed of cellulose, hemicellulose, and lignin, and cellulose is wrapped tightly by lignin, which makes it hard to use directly [28]. So, it is necessary to pretreat the biomass to separate lignin from cellulose sufficiently. DESs have been recently reported as having novel abilities to dissolve the lignin packaged in cellulose, thereby exposing the cellulose $[29,30]$.

DESs consist of an ammonium or phosphonium salt, such as choline chloride, and a hydrogen-bond donor (HBD). The properties of DESs can be easily changed by adjusting the type and molar ratios of the salt and HBD [30]. Here, choline chloride $(\mathrm{ChCl})$, and a HBD including formic acid (FA), lactic acid (LA), acetic acid (AA) were used to prepare DESs, and the molar ratio of $\mathrm{ChCl}$ and $\mathrm{HBD}$ was firstly set at 1:1. The selected biomass could be pretreated by DESs to different extents. DESs could show high solubility for lignin, while cellulose is found to be immiscible, and the lignin solubility could show a clear trend with the increase of the molar ratio of $\mathrm{ChCl}$ : $\mathrm{HBD}$. The observed phenomena were similar to those reported by other groups [30]. The contents of cellulose hydroxyl groups exposed on biomass could be evaluated by measuring the activation degree. As shown in Fig. 1A, in the presence of $\mathrm{ChCl}$ :LA (1:1), the activation degree for all of the biomasses was higher than that in ChCl:FA (1:1) and ChCl:AA (1:1). This finding was attributed to the possible variations in the network formed by hydrogen bonds, leading to different dissolved behaviors of the DESs [30]. The different activation degree was also observed in the same DES, and the activation degree of cornstalk, pasture, wheat straw, rice husk and PP pretreated by ChCl:LA (1:1) was $0.26,0.32,0.41,0.45$, and 0.51 , 
A

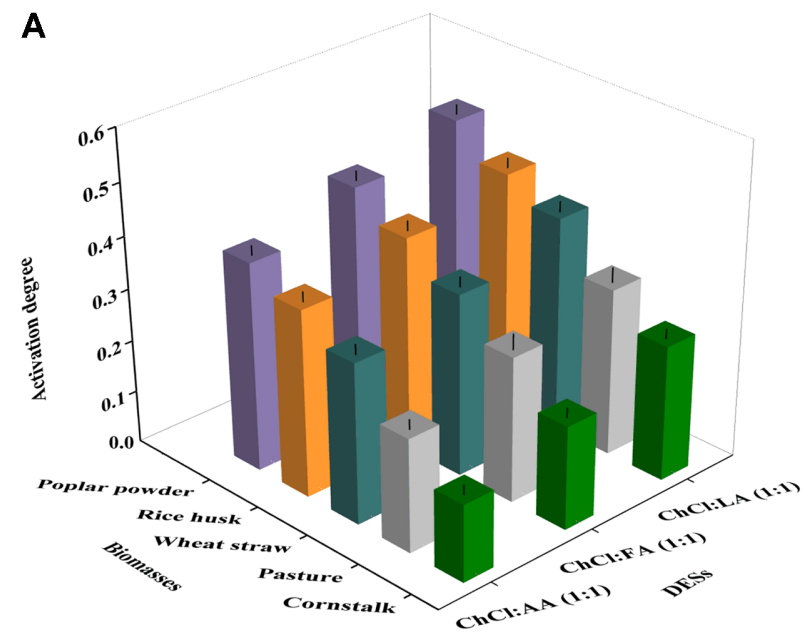

B

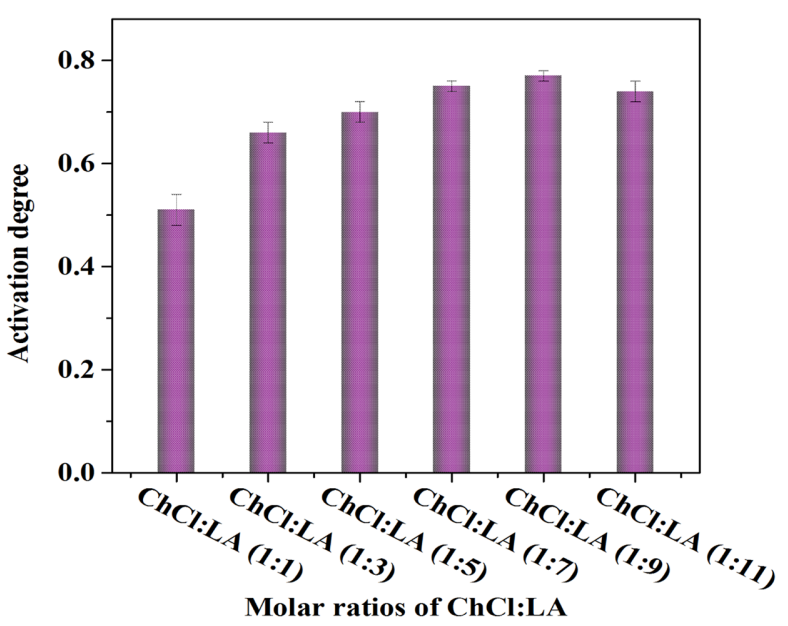

Fig. 1. Pretreatment of lignocellulosic biomass by DESs (A) and effects of ChCl: LA with different molar ratios on pretreatment of PP (B).

respectively. Because the activation degree of the biomasses was proportional to their respective content of cellulose hydroxyl groups, PP with high activation degree (0.51) indicated that its available hydroxyl group content was also high. So, PP was selected as a carrier for the subsequent immobilization of ER and GDH.

The effects of different molar ratios of $\mathrm{ChCl}$ : LA on PP pretreatment were then investigated. Fig. 1B shows that the activation degree of PP was improved with the increase of the molar ratios of $\mathrm{ChCl}$ : LA from 1:1 to $1: 9$, and a maximum activation degree of 0.77 was achieved at a molar ratio of $1: 9$ of $\mathrm{ChCl}$ : LA. It might be ascribed to the decreased viscosity of the DES with the increase of the amount of LA, which was beneficial to the mass transfer between the DES and PP, and it might be effective in disrupting inter- and intra-molecular hydrogen bonding in biomass [29]. A further increase in molar ratio to 1:11 slightly decreased the activation degree of PP. One possible explanation is that a small amount of cellulose might be dissolved simultaneously in the presence of a large amount of LA [30].

\section{Functionalization of Pretreated PP and Covalent Immobilization of ER and GDH}

After PP was pretreated, a large number of cellulose hydroxyl groups were exposed, however, the hydroxyl groups could not directly react with the amine groups on the enzymes to form covalent bonding. But cellulose hydroxyl groups can be used as an anchor point for functionalization. After such modification, the covalent binding between functionalized PP and enzyme can be significantly enhanced. Considered from the view of simple operation and effective cost, $\mathrm{NaIO}_{4}$ was firstly used to oxidize the hydroxyl groups on cellulose, introducing

Table 1. Functionalization of pre-treated PP and covalent immobilization of ER and GDH.

\begin{tabular}{|c|c|c|c|c|}
\hline Functional conditions of pre-treated PP & Enzymes (20 mg) & Immobilization efficiency (\%) & \multicolumn{2}{|c|}{ Activity recovery $(\%)$} \\
\hline $\mathrm{NaIO}_{4}$-oxidized PP & ER & 18.0 & \multicolumn{2}{|c|}{ N.D. } \\
\hline PEI $(8 \mathrm{mM})+$ glutaraldehyde $(50 \mathrm{mM})$ & ER & 26.1 & \multicolumn{2}{|c|}{5.1} \\
\hline PEI $(8 \mathrm{mM})+$ oxidized dextran $(40 \mu \mathrm{M})$ & ER & 28.5 & \multicolumn{2}{|c|}{14.8} \\
\hline Ethanediamine $(150 \mathrm{mM})+$ oxidized dextran $(40 \mu \mathrm{M})$ & ER & 20.2 & \multicolumn{2}{|c|}{6.4} \\
\hline Ethanediamine $(150 \mathrm{mM})+$ glutaraldehyde $(50 \mathrm{mM})$ & ER & 92.5 & \multicolumn{2}{|c|}{31.3} \\
\hline Ethanediamine $(150 \mathrm{mM})+$ glutaraldehyde $(50 \mathrm{mM})$ & & & ER & $\mathrm{GDH}$ \\
\hline Ethanediamine $(150 \mathrm{mM})+$ glutaraldehyde $(50 \mathrm{mM})$ & $\mathrm{ER}+\mathrm{GDH}$ & 85.7 & 10.2 & 9.6 \\
\hline
\end{tabular}

N.D.: not detectable. 


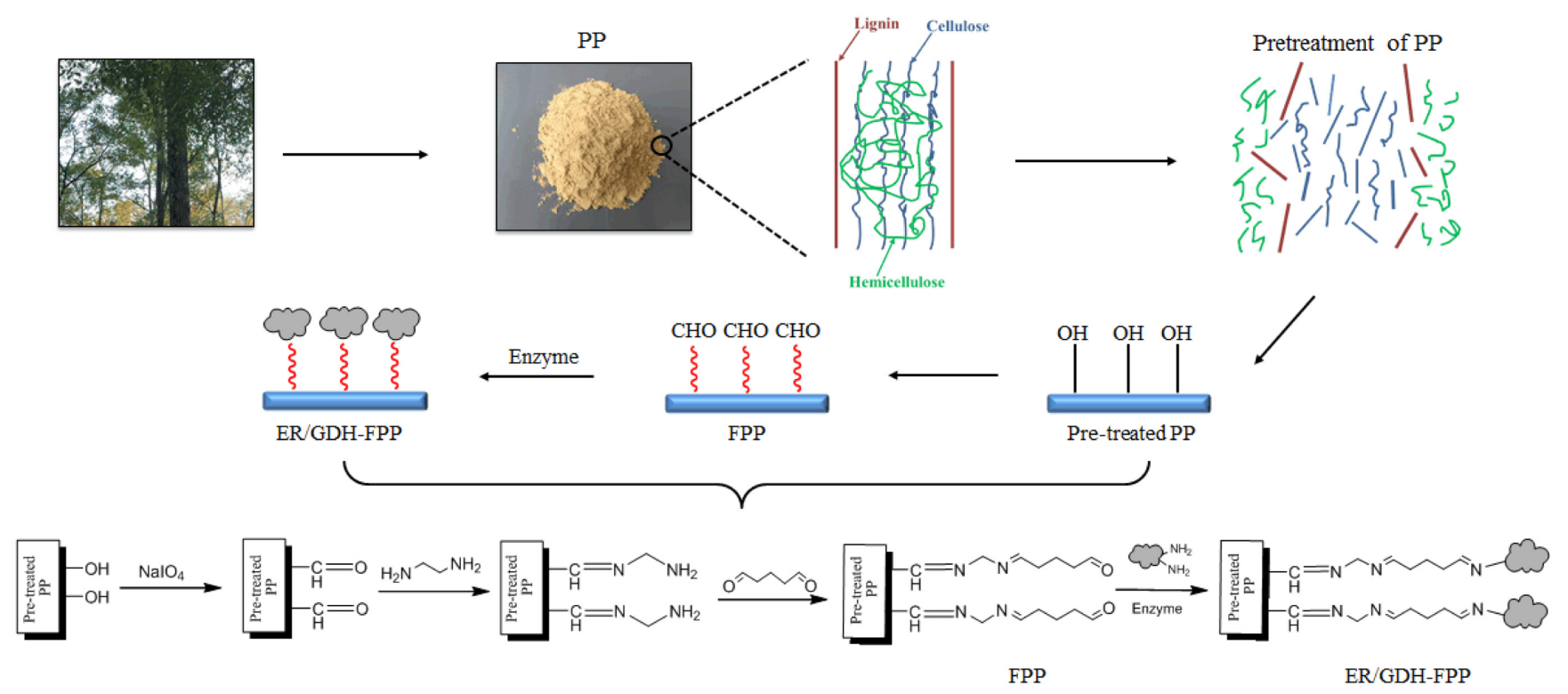

Scheme 1. Scheme of functionalization of pretreated PP and covalent immobilization of ER and GDH.

aldehyde groups on $\mathrm{PP}$, and then $\mathrm{NaIO}_{4}$-oxidized PP (OPP) was directly used to immobilize ER. The results in Table 1 show that OPP was weak in binding to ER, and the immobilization efficiency of ER-OPP was only $18.0 \%$.

With the above results, we considered further introducing an amine spacer arm on OPP, which might be beneficial to the immobilization of enzymes. Ethylenediamine or PEI were firstly selected to react with the aldehyde groups on $\mathrm{OPP}$, and then glutaraldehyde or oxidized dextran were used as a modifier to react with the amine groups, to finally obtain the functionalized PP (FPP) with an elongated spacer arm with the exposed aldehyde groups. Subsequently, the obtained FPP was used as a support material for the immobilization of ER and GDH. The functionalization of pretreated PP and the covalent immobilization of enzymes was listed in Scheme 1.

Table 1 shows that OPP was functionalized by a different combination of amine and aldehyde modifier, which can lead to different immobilization results. When PEI was selected as an amine modifier, whether glutaraldehyde or oxidized dextran was used, both the immobilization efficiency and activity recovery of ER-FPP were poor. For the combination of ethylenediamine and oxidized dextran, the immobilization results of ER-FPP were also not ideal. But it was found that ethylenediamine and glutaraldehyde were the excellent combination, and the immobilization efficiency and the activity recovery of ER-FPP were improved to $92.5 \%$ and $31.3 \%$, respectively. Under the same immobilization conditions, an immobilization efficiency of
$74.5 \%$ and activity recovery of $26.3 \%$ for GDH-FPP can also be obtained.

Because ER is a reductase, it is necessary to prepare coimmobilized ER and GDH, forming an in situ cofactor recycling system. In this case, the cofactor would be effectively recycled between ER and GDH. The available cofactor concentration on the carrier would be high, which could be easily used by ER in catalyzed reactions [31]. Based on this consideration, the co-immobilization of ER and GDH was carried out using FPP as a supporting material by covalent bonding. Unfortunately, both immobilization efficiency and activity recovery were much lower than that in single-immobilization of ER and GDH. So, ER-FPP and GDH-FPP were selected to be further investigated.

The concentration of modifiers had a significant effect on immobilization efficiency and activity recovery of ER-FPP and GDH-FPP. As shown in Fig. 2, the activity recovery of ER and GDH in ER-FPP or GDH-FPP was increased with an increase in the concentration of ethylenediamine (from $100 \mathrm{mM}$ to $300 \mathrm{mM}$ ) and glutaraldehyde (from $25 \mathrm{mM}$ to $100 \mathrm{mM}$ ). At ethylenediamine concentration at $300 \mathrm{mM}$ and glutaraldehyde concentration at $100 \mathrm{mM}$, the excellent immobilization efficiency and activity recovery of ER-FPP were $95.5 \%$ and $44.1 \%$, and that of GDH-FPP were $83.6 \%$ and $36.8 \%$, respectively. With further increase in the concentration of ethylenediamine and glutaraldehyde to $500 \mathrm{mM}$ and $200 \mathrm{mM}$, respectively, the activity of ER and GDH in ER-FPP and GDH-FPP was decreased, which might be due to the high level of functional groups of 

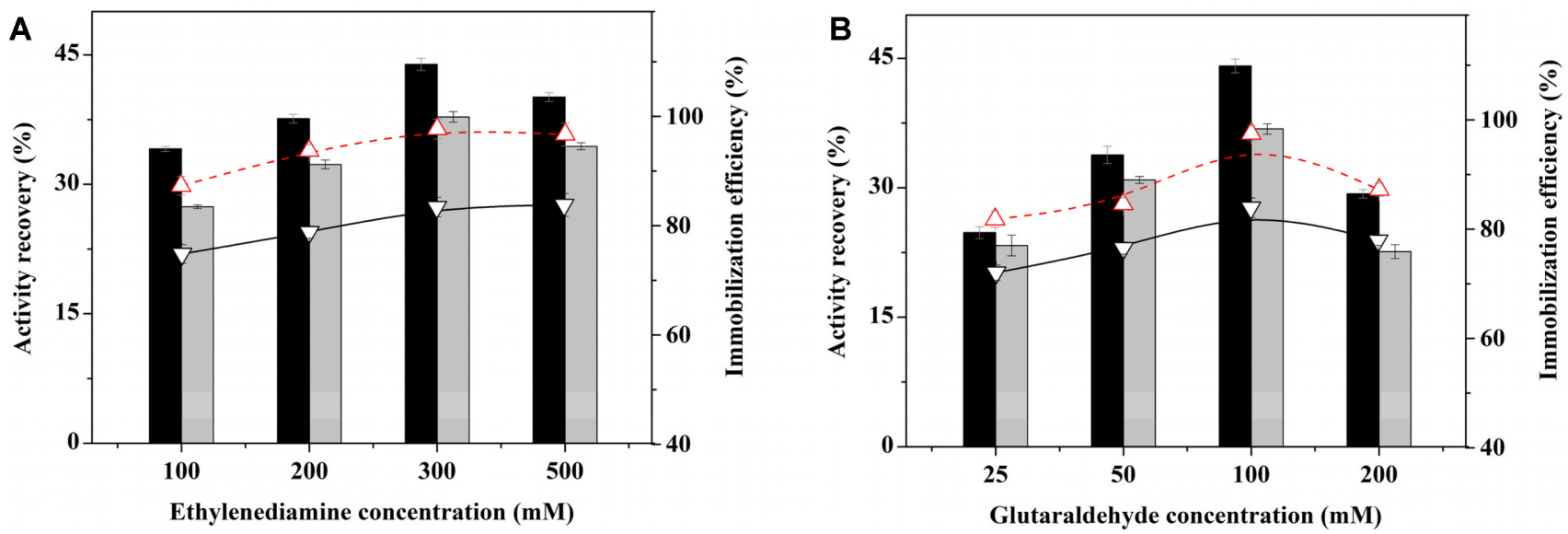

Fig. 2. Effects of the concentration of ethylenediamine (A) and glutaraldehyde (B) on immobilization of ER and GDH: activity recovery of ER-FPP ( $\square$ ) and GDH-FPP $(\square)$; immobilization efficiency of ER-FPP $(\triangle)$ and GDH-FPP $(\nabla)$.

ethylenediamine and glutaraldehyde, which led to excessive crosslinking of PP themselves and could not effectively provide binding sites for enzymes [32-34]. But all in all, FPP with simple pretreatment and functionalization, can be used as an excellent carrier for the immobilization of ER and GDH.

\section{Further Immobilization Optimization of ER-FPP and GDH-FPP}

Given that the immobilization efficiency and activity recovery of the immobilized ER and GDH can be easily affected by the environment, the major variable parameters, such as $\mathrm{pH}$ of Tris- $\mathrm{HCl}$ buffer, enzyme amount, and immobilization time were carefully optimized, and the data were listed in supplementary material. In all the optimized parameters, the $\mathrm{pH}$ of Tris- $\mathrm{HCl}$ buffer was an especially important parameter, which is because the established immobilization strategies were the formation of covalent bonds between aldehyde groups on FPP and lysine residues on enzyme. So, the immobilization process is sensitive to the environmental $\mathrm{pH}$, and the $\mathrm{pH}$ of Tris$\mathrm{HCl}$ buffer had a certain influence on the formation of imine [35]. When the buffer $\mathrm{pH}$ was over 7.5, the immobilization efficiency and activity recovery of ER-FPP and GDH-FPP were all decreased. Especially at high $\mathrm{pH}$ of 9.5, the immobilization efficiency and activity recovery of ER-FPP were only $41.6 \%$ and $7.2 \%$ respectively, while that of GDH-FPP were only $41.9 \%$ and $2.6 \%$, respectively (Fig. S1b). It might be because high alkaline $\mathrm{pH}$ could weakened the electrophilicity of the carbonyl groups in the aldehyde groups on FPP, which was unfavorable in reacting with the amine groups on protein surfaces, resulting in the decrease of the reaction activity. Also, the decreased activities of enzyme itself at high $\mathrm{pH}$ of Tris- $\mathrm{HCl}$ buffer might in turn also have a close relationship with the poor immobilization results of ER-FPP and GDH-FPP.

The activity recovery of ER-FPP and GDH-FPP was also significantly influenced by enzyme amount and immobilization time (Figs. S1a and S1c, respectively). The influence trends of various parameters were similar to each other and the activity recovery of ER-FPP and GDH-FPP increased with ER and GDH amount from $10 \mathrm{mg}$ to $30 \mathrm{mg}$, as did the immobilization time from $1 \mathrm{~h}$ to $3 \mathrm{~h}$. Further increasing the values of all corresponding parameters decreased the activity of ER-FPP and GDH-FPP, which might be due to the aggregation of the immobilized ER and GDH, reducing the accessibility of enzyme particles to substrates. The maximum immobilization efficiency of $95.1 \%$ and $84.7 \%$, and activity recovery of $47.5 \%$ and $37.8 \%$ for ER and GDH, respectively, was achieved at Tris- $\mathrm{HCl}$ buffer $(50 \mathrm{mM}$, pH 7.5), ER amount (30 mg), GDH amount (30 mg), and immobilization time (3 h).

\section{Morphological Characterization of Untreated PP, FPP and ER-FPP}

SEM reveals that the morphologies of PP were varied with the changing processes of pretreatment, functionalization and immobilization. The untreated PP had a smooth surface, and the lignocellulosic structure was complete (Fig. 3A). For PP pretreated by DESs, the surface became loose and coarse, and displayed a 'peeling' appearance (Fig. 3B). Combined with experimental data, we think the lignin of PP can be effectively removed by DES. After the pretreated PP was functionalized by ethylenediamine and 

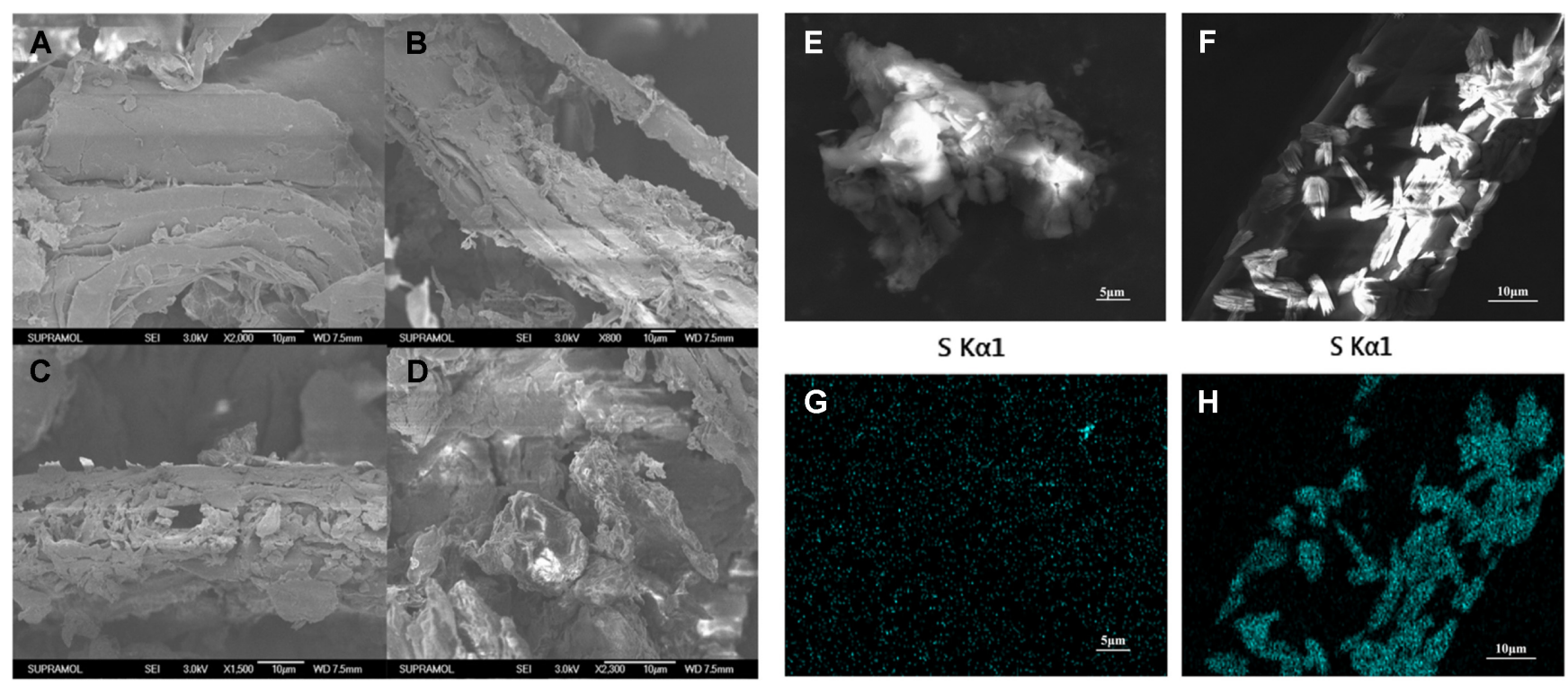

Fig. 3. SEM images of untreated PP (A); pretreated PP (B); FPP (C); ER-FPP (D). EDS images of the full extent of FPP (E) and ERFPP (F). Distribution of S element on the surface of FPP $(\mathbf{G})$ and ER-FPP $(\mathbf{H})$.

glutaraldehyde, a porous, crosslinked blocky structure with on the FPP surface was observed (Fig. 3C), which has a close relationship with the functionalized modification. When ER was covalently bound to FPP, the surface pore size of FPP became smaller (Fig. 3D).

To further confirm the successful binding of ER onto FPP, EDS was used to analyze and compare the sulfur (S) element distribution on the surface of FPP and ER-FPP. On the basis of the full extent of FPP (Fig. 3E) and ER-FPP (Fig. 3F), it was observed that large amounts of $S$ elements were distributed on ER-FPP (Fig. $3 \mathrm{H}$ ), and not on FPP (Fig. 3G). Because $S$ elements are characteristic elements of protein, the results indicated that ER had been successfully immobilized on FPP.

\section{Thermal Stabilities of ER-FPP and GDH-FPP}

The thermal stabilities of free and immobilized ER and GDH were examined because of their importance in industrial applications. Free and immobilized ER and GDH were firstly incubated at a temperature of $30^{\circ} \mathrm{C}$ for $10 \mathrm{~h}$, where $30^{\circ} \mathrm{C}$ was selected because the subsequently continuous conversions of 4-(4-Methoxyphenyl)-3-buten-2-one were carried out at $30^{\circ} \mathrm{C}$. Figs. $4 \mathrm{~A}$ and $4 \mathrm{~B}$ shows that free ER and GDH had lost $30 \%$ and $50 \%$ of their initial activity after $10 \mathrm{~h}$ of heat treatment, respectively, whereas ER-FPP and GDH-FPP still maintained their nearly entire initial activity. In order to further confirm the immobilized enzymes could exhibit excellent thermal stabilities, a much high tempera- ture of $50^{\circ} \mathrm{C}$ was subsequently used. After $8 \mathrm{~h}$ of heat treatment, ER-FPP and GDH-FPP kept $82.3 \%$ and $55.7 \%$ of their initial activity, respectively, whereas free ER had approximately only $9.2 \%$ of its initial activity, and free GDH had already lost all its activity after one hour (Figs. 4C and 4D). The enhanced thermal stabilities of immobilized ER and GDH have a close relationship with the immobilization, which can create a much more suitable microenvironment for enzyme, thus making the enzyme denaturation difficult.

\section{Continuous Conversions of 4-(4-Methoxyphenyl)-3-Buten- 2-One}

To certify whether ER-FPP and GDH-FPP can effectively recycle the cofactor, the optimized immobilized enzymes were used to test the recycling system in continuous conversions of 4-(4-Methoxyphenyl)-3-buten-2-one to prepare 4-(4-Methoxyphenyl)-butan-2-one, which is an important fine chemical and is used extensively in several consumer products such as raspberry scent, food additives and insect attractants as well as in the preparation of melanin formation inhibitors [36]. 4-(4-Methoxyphenyl)- 3-buten-2one was supplied to the system in $50 \mu \mathrm{M}$ increments to a total of $350 \mu \mathrm{M}$. NAD $(100 \mu \mathrm{M})$ was supplied to initiate the reaction. The coupling of ER and GDH activities was evidenced by the continuous formation of 4-(4-Methoxyphenyl)butan-2-one for $56 \mathrm{~h}$ without further cofactor addition. The results in Fig. 5 show that the reaction conversion increased 

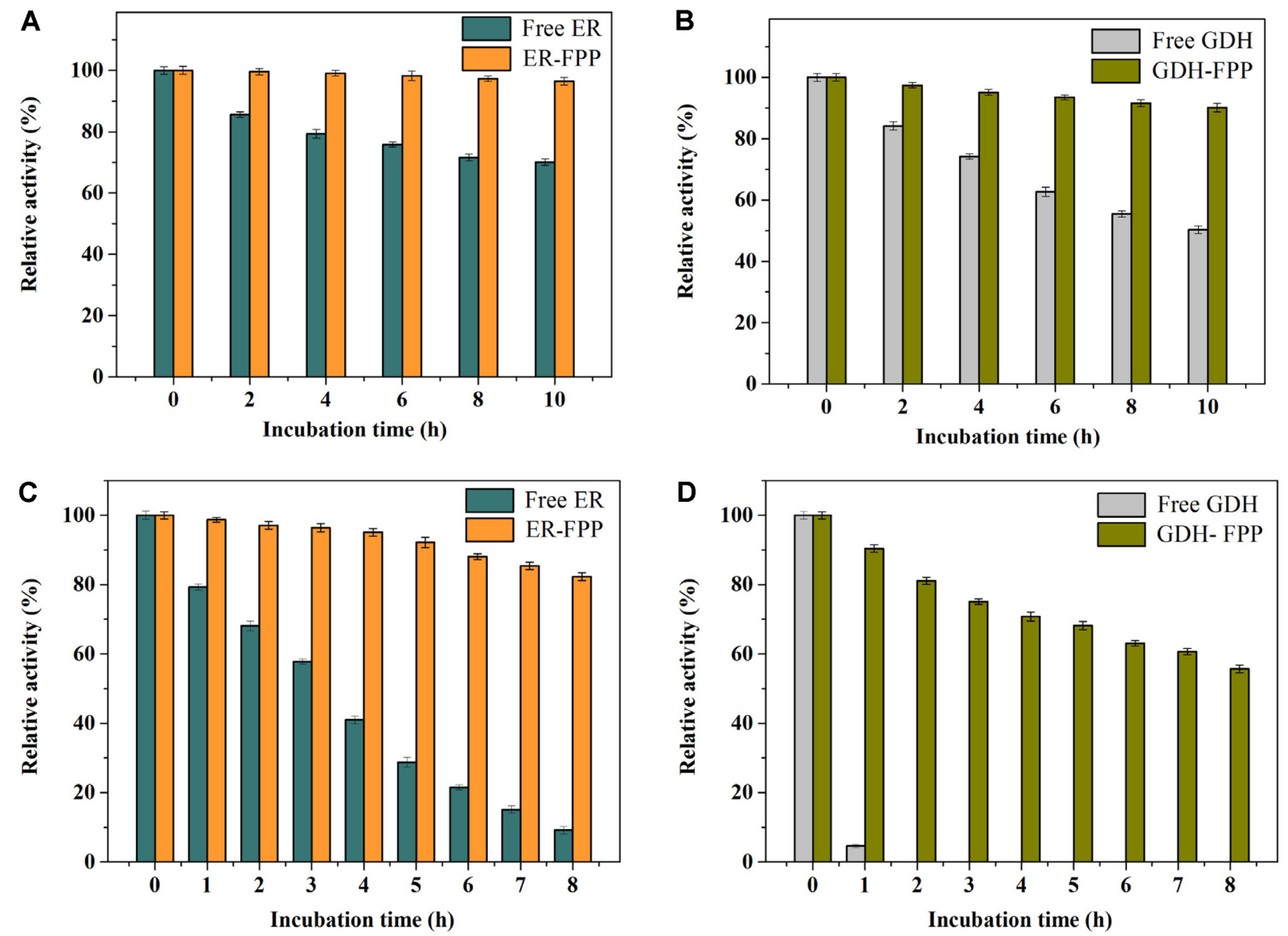

Fig. 4. Thermal stabilities of free and immobilized ER and GDH: incubation at $30^{\circ} \mathrm{C}(\mathbf{A})$ and $(\mathbf{B})$; incubation at $50^{\circ} \mathrm{C}(\mathbf{C})$ and $(\mathbf{D})$.

steadily in the first five additions of substrate, and after the sixth addition of substrate, the conversion rate increased slowly. Despite this, the total reaction conversion could

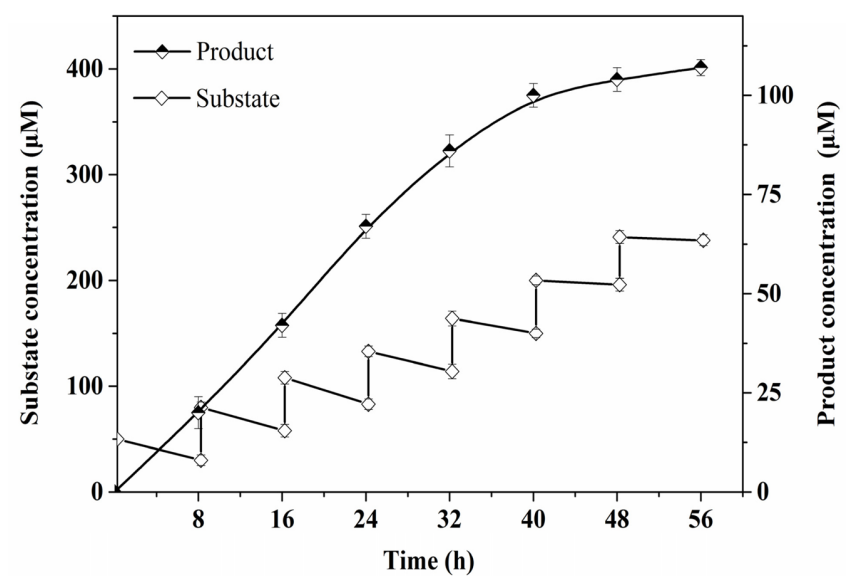

Fig. 5. Continuous conversions of 4-(4-Methoxyphenyl)-3buten-2-one by ER-FPP and GDH-FPP. still reach to $30.6 \%$, and $107 \mu \mathrm{M}$ of 4-(4-Methoxyphenyl)butan-2-one could be finally obtained, which indicated that the immobilization strategy established here can effectively achieve a cofactor regeneration system.

\section{Recovery and Reusability of ER-FPP and GDH-FPP}

Generally, free enzymes are difficult to recover and reuse. Recovery and reusability of ER-FPP and GDH-FPP are therefore important aspects to be tested in this study. We studied the durability of immobilized ER and GDH through a repeated batch reduction of 4-(4-Methoxyphenyl)3-buten-2-one at $30^{\circ} \mathrm{C}$. After $3 \mathrm{~h}$ for each run, the immobilized enzyme mixture was filtered off, washed with Tris- $\mathrm{HCl}$ buffer, and reused with fresh substrates. The relative ER activities of the mixture of ER-FPP and GDH-FPP after several times of recycling were illustrated in Fig. 6. The mixture of ER-FPP and GDH-FPP could retain over $80 \%$ of its initial ER activity in the first eight cycles, and $61.4 \%$ of its initial ER activity could still be observed after fourteen cycles. These obtained results indicate that covalent 


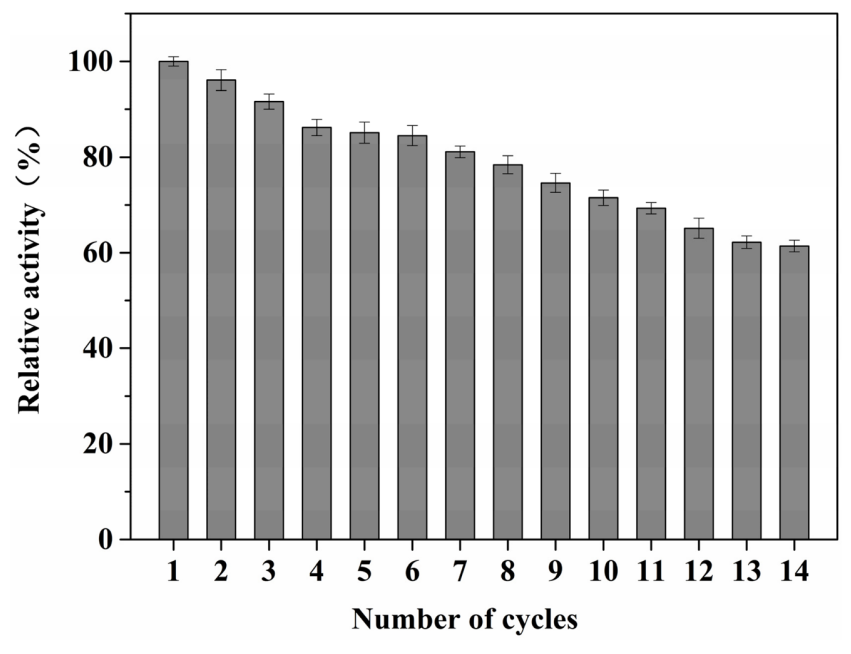

Fig. 6. Recovery and reusability of ER-FPP and GDH-FPP.

immobilization ensures the reusability of biocatalyst, and allows the biocatalyst to be continuous recycled.

In summary, covalent immobilized ER-FPP and GDHFPP were successfully constructed with FPP as a support material. The thermal stability and reusability of ER-FPP and GDH-FPP were superior to that from free ER and GDH. The immobilized ER and GDH can also be applied in the continuous conversions of 4-(4-Methoxyphenyl)-3-buten-2one, and the cofactor regeneration system can be effectively recycled. This study exploited a simple and cost-effective method of immobilization and application for ER and its cofactor recycling system.

\section{Acknowledgements}

The authors are grateful for the financial support provided by the National Natural Science Foundation of China (Nos. 21672081 and 21372098), Jilin Provincial Science and Technology Sustentation Program (Nos. 20160204004SF and 20190201165JC), the Jilin Province Development and Reform Commission (Nos. 2016C047-1).

\section{Conflict of Interest}

The authors have no financial conflicts of interest to declare.

\section{References}

1. Gao X, Ren J, Wu Q, Zhu D. 2012. Biochemical characterization and substrate profiling of a new NADH-dependent enoate reductase from Lactobacillus casei. Enzyme Microb. Technol. 51: 26-34.

2. Stuermer R, Hauer B, Hall M, Faber K. 2007. Asymmetric bioreduction of activated $\mathrm{C}=\mathrm{C}$ bonds using enoate reductases from the old yellow enzyme family. Curr. Opin. Chem. Biol. 11: 203-213.

3. Mélanie H, Stueckler C, Hauer B, Stuermer R, Friedrich T, Breuer $\mathrm{M}$, et al. 2008. Asymmetric bioreduction of activated $\mathrm{C}=\mathrm{C}$ bonds using Zymomonas mobilis NCR enoate reductase and old yellow enzymes OYE 1-3 from yeasts. Eur. J. Org. Chem. 2008: 1511-1516.

4. Winkler CK, Tasnádi G, Clay D, Hall M, Faber K. 2012. Asymmetric bioreduction of activated alkenes to industrially relevant optically active compounds. J. Biotechnol. 162: 381389.

5. Schittmayer M, Glieder A, Uhl MK, Winkler A, Zach S, Schrittwieser JH, et al. 2011. Old yellow enzyme-catalyzed dehydrogenation of saturated ketones. Adv. Synth. Catal. 353: 268-274.

6. Stueckler C, Hall M, Ehammer H, Pointner E, Kroutil W, Macheroux $\mathrm{P}$, et al. 2007. Stereocomplementary bioreduction of $\alpha$, $\beta$-unsaturated dicarboxylic acids and dimethyl esters using enoate reductases: enzyme- and substrate-based stereocontrol. Org. Lett. 9: 5409-5411.

7. Turrini NG, Hall M, Faber K. 2015. Enzymatic synthesis of optically active lactones via asymmetric bioreduction using ene-reductases from the old yellow enzyme family. Adv. Synth. Catal. 357: 1861-1871.

8. Donk WACD, Zhao H. 2003. Recent developments in pyridine nucleotide regeneration. Curr. Opin. Biotechnol. 14: 421-426.

9. Endo T, Koizumi S. 2001. Microbial conversion with cofactor regeneration using genetically engineered bacteria. Adv. Synth. Catal. 343: 521-526.

10. Franssen MCR, Steunenberg P, Scott EL, Zuilhof H, Sanders JPM. 2013. Immobilised enzymes in biorenewables production. Chem. Soc. Rev. 42: 6491-6533.

11. Betancor L, Berne C, Luckarifta HR, Spain JC. 2006. Coimmobilization of a redox enzyme and a cofactor regeneration system. Chem. Commun. 34: 3640-3642.

12. Dicosimo R, Mcauliffe J, Poulose AJ, Bohlmann G. 2013. Industrial use of immobilized enzymes. Chem. Soc. Rev. 42: 6437-6474.

13. Adlercreutz P. 2013. Immobilisation and application of lipases in organic media. Chem. Soc. Rev. 42: 6406-6436.

14. Wang Y, Zhang X, Han N, Wu Y, Wei D. 2018. Oriented covalent immobilization of recombinant protein A on the glutaraldehyde activated agarose support. Int. J. Biol. Macromol. 120: 100-108.

15. Zucca P, Lafuente RF, Sanjust E. 2016. Agarose and its derivatives as supports for enzyme immobilization. Molecules 21: $1-25$. 
16. Osuna Y, Sandoval J, Saade H, López RG, Martinez JL, Colunga EM, et al. 2015. Immobilization of Aspergillus niger lipase on chitosan-coated magnetic nanoparticles using two covalent-binding methods. Bioprocess Biosyst. Eng. 38: 1437-1445.

17. Krajewska B. 2004. Application of chitin- and chitosan-based materials for enzyme immobilizations: a review. Enzyme Microb. Technol. 35: 126-139.

18. Li K, Chen ZB, Liu DL, Zhang L, Tang Z, Wang Z, et al. 2018. Design and synthesis study of the thermo-sensitive copolymer carrier of penicillin G acylase. Polym. Adv. Technol. 29: 1902-1912.

19. Li K, Liu XT, Zhang XF, Liu D, Zhang XY, Ma SM, et al. 2019. The engineering and immobilization of penicillin $G$ acylase onto thermo-sensitive tri-block copolymer system. Polym. Adv. Technol. 30: 86-93.

20. Yilmaz E, Can K, Sezgin M, Yilmaz M. 2011. Immobilization of Candida rugosa lipase on glass beads for enantioselective hydrolysis of racemic Naproxen methyl ester. Bioresour. Technol. 102: 499-506.

21. Hosseini SH, Hosseini SA, Zohreh N, Yaghoubi M, Pourjavadi A. 2018. Covalent immobilization of cellulase using magnetic poly (ionic liquid) support: improvement of the enzyme activity and stability. J. Agric. Food Chem. 66: 789-798.

22. Poojari Y, Clarson SJ. 2013. Thermal stability of Candida antarctica lipase B immobilized on macroporous acrylic resin particles in organic media. Biocatal. Agric. Biotechnol. 2: 7-11.

23. Cantone S, Ferrario V, Corici L, Ebert C, Fattor D, Spizzo P, et al. 2013. Efficient immobilisation of industrial biocatalysts: criteria and constraints for the selection of organic polymeric carriers and immobilisation methods. Chem. Soc. Rev. 42: 6262-6276.

24. Tuck CO, Pérez E, Horváth IT, Sheldon RA, Poliakoff M. 2012. Valorization of biomass: deriving more value from waste. Science 337: 695-699.

25. Parveen K, Diane MB, Michael JD, Pieter S. 2009. Methods for pretreatment of lignocellulosic biomass for efficient hydrolysis and biofuel production. Ind. Eng. Chem. Res. 48: 3713-3729.
26. Li H, Xiao W, Xie P, Zheng L. 2018. Co-immobilization of enoate reductase with a cofactor-recycling partner enzyme. Enzyme Microb. Technol. 109: 66-73.

27. Tian X, Zhang S, Zheng L. 2016. Enzyme-Catalyzed Henry reaction in choline chloride-based deep eutectic solvents. $J$. Microbiol. Biotechnol. 26: 80-88.

28. Francisco M, Bruinhorst VDA, Kroon MC. 2012. New natural and renewable low transition temperature mixtures (LTTMs): screening as solvents for lignocellulosic biomass processing. Green Chem. 14: 2153-2157.

29. Lynam JG, Reza MT, Vasquez VR, Coronella CJ. 2012. Pretreatment of rice hulls by ionic liquid dissolution. Bioresour. Technol. 114: 629-636.

30. Lynam JG, Kumar N, Wong MJ. 2017. Deep eutectic solvents' ability to solubilize lignin, cellulose, and hemicellulose; thermal stability; and density. Bioresour. Technol. 238: 684-689.

31. Javier RM, Rivas BDL, Rosario M, Guisán JM, Fernando LG. 2012. Rational co-immobilization of bi-enzyme cascades on porous supports and their applications in bio-redox reactions with in situ recycling of soluble cofactors. ChemCatChem 4: 1279-1288.

32. Migneault I, Dartiguenave C, Bertrand MJ, Waldron KC. 2004. Glutaraldehyde: behavior in aqueous solution, reaction with proteins, and application to enzyme crosslinking. Biotechniques 37: 790-802.

33. Barbosa O, Ortiz C, Murcia AB, Torres R, Rodrigues RC, Lafuente RF. 2014. Glutaraldehyde in bio-catalysts design: a useful crosslinker and a versatile tool in enzyme immobilization. RSC Adv. 4: 1583-1600.

34. Wine Y, Hadar NC, Freeman A, Frolow F. 2007. Elucidation of the mechanism and end products of glutaraldehyde crosslinking reaction by X-ray structure analysis. Biotechnol. Bioeng. 98: 711-718.

35. Brady D, Jordaan J. 2009. Advances in enzyme immobilization. Biotechnol. Lett. 31: 1639-1650.

36. Morad M, Nowicka E, Douthwaite M, Iqbal S, Miedziak P, Edwards JK, et al. 2017. Multifunctional supported bimetallic catalysts for a cascade reaction with hydrogen auto transfer: synthesis of 4-phenylbutan-2-ones from 4-methoxybenzyl alcohols. Catal. Sci. Technol. 7: 1928-1936. 